Article

\title{
Occupational Exposure on Board Fishing Vessels: Risk Assessments of Biomechanical Overload, Noise and Vibrations among Worker on Fishing Vessels in Southern Italy
}

\author{
Francesca Mansi ${ }^{1}$ (D), Enza Sabrina Silvana Cannone ${ }^{1}$, Antonio Caputi ${ }^{1}$, Luigi De Maria ${ }^{1}$, \\ Leonardo Lella ${ }^{2}$, Domenica Cavone ${ }^{1}$ and Luigi Vimercati ${ }^{1, *(D)}$ \\ 1 University Hospital Policlinico, Unit of Occupational Medicine, Interdisciplinary Department of \\ Medicine (DIM), School of Medicine, University of Bari Aldo Moro, 70124 Bari, Italy; \\ francesca.mansi@uniba.it (F.M.); enza.cannone@uniba.it (E.S.S.C.); antonio.caputi@live.it (A.C.); \\ luigi.demaria@uniba.it (L.D.M.); domenica.cavone@uniba.it (D.C.) \\ 2 Local Health Service Taranto, Viale Virgilio 31, 74122 Taranto, Italy; dinolella1967@gmail.com \\ * Correspondence: luigi.vimercati@uniba.it
}

Received: 28 October 2019; Accepted: 16 December 2019; Published: 17 December 2019

\begin{abstract}
Sea fishing is one of the sectors with the highest risk of illness and work-related accidents. The purpose of the study is to evaluate the exposure of fishing workers to three major risks: biomechanical overload, noise, and whole-body vibrations. We used common methods and measurement tools in the field: observational video analysis, questionnaires, and direct measurement. Noise and vibrations levels were measured aboard five boats belonging to the main fishing communities of Southern Italy. The random sample consisted of 310 workers, of whom 108 agreed to complete a questionnaire to collect data on the perception of occupational risk and self-perception of health conditions. We found that fishermen had a high prevalence of osteoarticular pathologies $(42 \%)$ and that the biomechanical overload risk is mainly related to handling manual loads. Furthermore, the results indicate that the levels of weekly noise exposure exceed the exposure limit value of 87 decibel A (dBA) for fishing workers, and that the most noisiest area is the engine room. Exposure levels to whole-body vibrations were below $<0.5 \mathrm{~m} / \mathrm{s}^{2}$. Knowledge on occupational hazards and health effects in the fisheries sector should be used to develop ship technology, raise awareness of the correct use of personal protective equipment, and improve health surveillance of these workers.
\end{abstract}

Keywords: fishermen; biomechanical overload; noise; whole-body vibrations; occupational hazards

\section{Introduction}

Fishing plays a crucial role in employment and economic activity in several countries globally, with 40.3 million engaged workers [1]. In Europe, Italy is one of the countries with the highest level of employment in this sector; in particular, the Apulia region has high fishing activity, involving 6000 employees and 1962 fishing vessels [2].

Sea fishing is one of the sectors with the highest risks of illness and work-related accidents. Indeed, this professional group faces a set of adverse working conditions that can cause serious injury or damage to their health [3]. The International Labour Organization (ILO) states that the fishing sector has one of the highest workplace fatality rates, with approximately 24,000 worker deaths each year [4].

According to the World Health Organization (WHO), maritime work presents specific occupational risks. Among these are risks related to physical agents (e.g., ultraviolet radiation, extreme weather conditions, noise, and whole-body vibrations), biological agents (e.g., bacteria, viruses, fungi, toxins, 
and parasites) and psychosocial stressors, such as fatigue, excessive and irregular working hours, limited vessel space, lack of quality of sleep, and lack of hygiene [5].

On fishing vessels, the risk of biomechanical overload is mainly due to prolonged tasks in awkward positions, such as pushing and pulling, the manual handling of heavy loads and repetitive hand-arm movements [6,7]. These tasks are performed on an unstable platform and generally in a cold climate, leading to greater tension in standing workers. Therefore, workers on fishing vessels, similar to other professionals, are exposed to several risk factors that contribute to the development of work-related musculoskeletal disorders (WMSDs) [8,9].

Furthermore, these employees can be exposed to inhaled toxicants (i.e., gasoline, diesel oil, lubricants, gases, and vapours) and carcinogens, such as polycyclic aromatic hydrocarbons (PHAs), caused by the incomplete combustion of organic materials (i.e., coal, oil, petrol, and wood), or asbestos [10-15]. This mineral was widely used in the construction of hulls, hydraulic hoses, containers and engine rooms before it was classified as carcinogen in humans by the International Agency for Research on Cancer (IARC 1973) [16].

Although there is a high prevalence of chronic diseases among workers on fishing vessels compared to the general population, these workers are rarely subjected to health surveillance programmes. In particular, the fishing sector is characterized by a high prevalence of osteoarticular diseases $(57 \%)$, followed by hearing disorders $(27 \%)$, allergic diseases $(23 \%)$, cardiovascular diseases $(13 \%)$, respiratory illness (12\%), and skin disorders (8\%) [17].

In Italy, the regulation of the protection of workers' health and safety on merchant shipping and fishing vessels is regulated by legislative decrees $n^{\circ} 271$ and $n^{\circ} .298$, established in 1999, and the Ministry of Health is responsible for the health monitoring of ship workers by physicians of the Sea and Air Border Health Department (ISMAF), as well as occupational physicians [18,19].

There are few studies about occupational risk in fishing sector. Svendsen et al showed high noise levels in engine rooms (range 96-108 dBA) and lower values in the control cabins (range 70-90 dBA) on board Norwegian ships [20]. In Italy, Rapisarda et al conducted a phonometric study on six fishing vessels and they also found that the equivalent sound pressure level in the engine rooms consistenly exceeded $90 \mathrm{dBA}$ on all vessels [21]. Later, also Perretti et al. recorded values close to $90 \mathrm{dBA}$ in the same rooms [22]. A recent study carried out on the Gulf coast fishing vessels highlighted dangerous noise levels in engine rooms ranging from 94.8 to $105.0 \mathrm{dBA}$ [23].

Ship noise is gaining a lot of attention also from a noise impact on citizen's point of view. In fact, knowing the emitting source, is important to avoid noise high noise exposure and noise complaints to citizens living in the nearby of port and avoid the well-known effects compromising people health [24]. In order to prevent these, also in port areas, in the very recent years, studies are growing exploring the noise emitted by ships, with a special focus on fishing vessels [25].

As regarding to vibrations, Pinto et al found that daily exposure to vibrations on board fishing vessels varied according to sea conditions with values ranging between 0.2 and $0.3 \mathrm{~m} / \mathrm{s}^{2}$ [26].

The high prevalence of musculoskeletal disorders (MSDs) in fisheries is confirmed by several research studies. A cross-selectional study in a sample of 465 fishermen revealed that the prevalence of musculoskeletal symptoms was 61\% (95\%; CI: 56.6-65.4\%) [27]. In a recent study Frantzeskou et al conducted an interviewer-administered questionnaire to a random sample of 172 fishermen in North-Eastern Greece and they found high prevalence (77\%) of MSDs in group over 50 of age [28].

Of all the different and numerous risks to which workers are exposed in fishing activities, in our study we focused on the following three major ones: biomechanical overload, noise, and whole body vibrations. The purpose of the paper is to evaluate the exposure of fishing workers to these risks in 310 fishermen of the main fishing communities of Apulia Region, Southern Italy.

\section{Methods}

Data were extracted from the "The Safe Fishing Project", which aims to characterize the risk factors to which workers on fishing vessels are exposed in the course of their employment in the main 
fishing communities in the Apulia region [29]. The overall sample consisted of 310 workers, of whom $108(34.8 \%)$ participated in the study. The selection of the sample was carried out on a random basis and the 108 participating fishermen expressed interest in a survey of occupational risks aboard their vessels, such as and biomechanical overload, noise, whole-body vibrations.

The five fishing vessels involved in the study had a gross weight of less than 20 tons, a length of less than 24 metres and wooden decks and hulls. The fishing type performed was "trawl fishing". Table 1 shows the working time on board.

Table 1. Working time on board.

\begin{tabular}{cc}
\hline Work week & $\begin{array}{c}24 \mathrm{~h} \text { a day, } 5 \text { days a week (from midnight Sunday to midnight Thursday). } \\
\text { Activities were spread over } 4 \text { work shifts and } 4 \mathrm{~h} \text { of rest within } 24 \mathrm{~h} .\end{array}$ \\
\hline $\begin{array}{c}\text { Two working days } \\
\text { Working day }\end{array}$ & $\begin{array}{c}48 \mathrm{~h} \\
\text { Approximately } 16 \mathrm{~h}\end{array}$ \\
\hline
\end{tabular}

\subsection{Biomechanical Overload}

Risk assessments were performed for different types of fishing, such as trawl fishing, longline fishing, and mussel cultivation, by applying the ISO 11228-1/2/3 standard [30-32].

The ISO 11228-3 standard chose OCRA (Occupational Repetitive Action) as the preferred method to measure the risk of biomechanical overload of the upper limbs. The OCRA checklist is used to draw up an initial map of the risk of the presence of repetitive work. The map makes it possible to determine what proportion of the jobs or tasks can be classified as green (no risk), yellow (significant or borderline risk), red (medium risk), or purple (high risk) [33]. According to ISO 3, the rapid upper limb assessment (RULA) method is among the other methods used to assess the risk of biomechanical overload of the upper limbs. RULA is a screening tool that assesses biomechanical and postural loading on the whole body with particular attention to the neck, trunk, and upper limbs. A RULA assessment requires little time to complete and the scoring generates an action list which indicated the level of intervention required to reduce the risks of injury due to physical loading on the operator [34].

The evaluation of the repetitive upper limbs movements was carried out by the researchers. The worker's body posture was recorded during the whole working day (about $16 \mathrm{~h}$ ) by a video camera. It was recorded carefully from beginning to end of the work by direct observation method employing video-photography on the job (Figures 1-3).

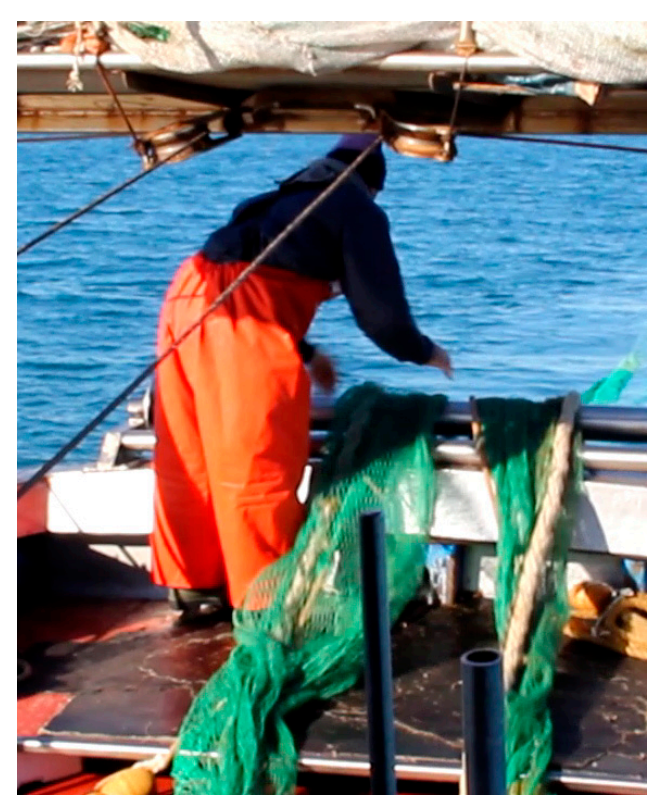

Figure 1. Fisherman during the activity of manual handling fishing nets. 


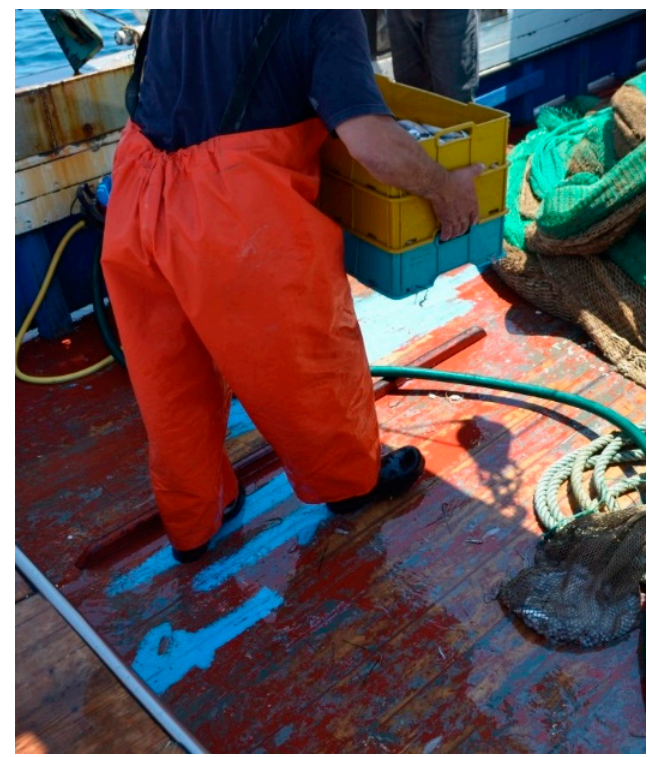

Figure 2. Fisherman during the activity of manual handling fishing boxes.

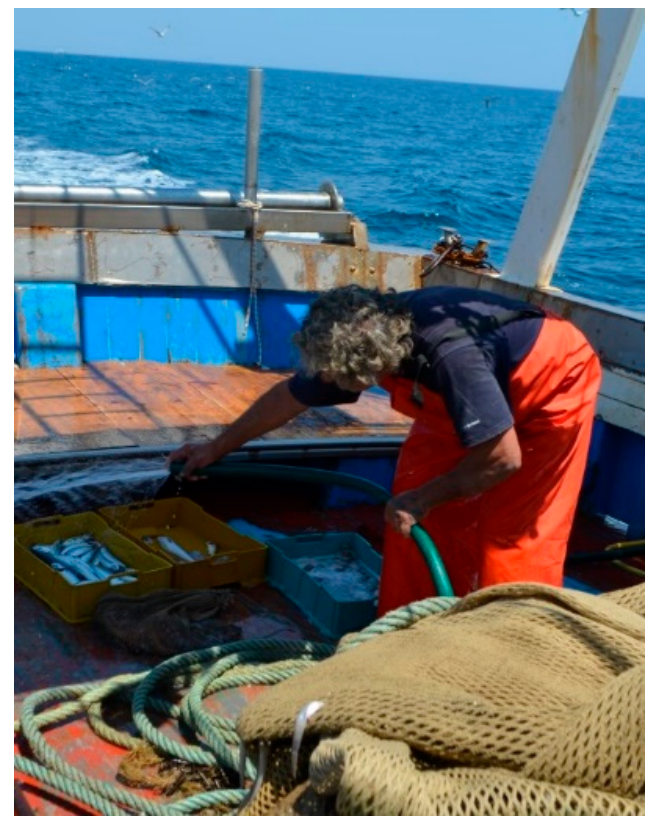

Figure 3. Fisherman at work in awkward positions.

To evaluate the risk of biomechanical overload, negative factors, such as platform instability, thermal excursion between cold rooms and external environments and extreme weather conditions, were considered.

\subsection{Noise}

A Svantek 948 multichannel-Svantek Italy Srl, Milan-analyzer (equipped with a microphone, preamplifier, and Svan PC acquisition/processing software) was used to measure the sound level. Risk assessment was performed by applying the UNI 9432 and UNI EN ISO 9612 standards [35,36].

Phonometric measurements were carried out during both the navigation phases and fishing activity phases. During the noise measurement procedures, we acquired the frequency values. The values were acquired in one-third octave band measurements from $20 \mathrm{~Hz}$ to $20,000 \mathrm{~Hz}$. 
Surveys were conducted in various areas of the boats, such as the aft deck, the central deck area, the engine room, the interior of control cabin, the lunchroom/kitchen, and the rest area of the berths.

The boat areas and the activities identified for phonometric measurements were agreed upon during an interview with the operating staff (Table 2).

Table 2. Activities and measurement stations.

\begin{tabular}{cccc}
\hline Activities & Measurement Stations & T Exp Sunday (m) & T Exp Weekdays (m) \\
\hline Preparation (preparatory activities) & Winch & 10 & 10 \\
Port departure & Winch & 60 & 30 \\
Towing nets & Winch (engine room door open) & - & 180 \\
Towing nets & Winch (engine room door closed) & - & - \\
Return to port & Control cabin & 60 & - \\
Return to port & Winch and open deck & 270 & 30 \\
Towing nets & Open deck & 120 & 120 \\
Hauling nets & Winch & 120 & 90 \\
Hauling nets & Berth & - & - \\
Hauling nets & Engine room & & \\
\hline
\end{tabular}

\subsection{Whole-Body Vibration}

Whole-body vibrations were measured by a Svantek 948 multichannel-Svantek Italy Srl, Milan-analyzer (equipped with Bruel \& Kjaer 4322 tri-axial accelerometer and Svan PC acquisition/processing software), and by applying the UNI ISO 2631-1 standard [30].

The measurements of whole-body vibrations were also carried out during normal navigation to reach the fishing zone and during fishing activities.

Similarly, measurements were conducted in the same areas of the ship used for the phonometric surveys.

In the control cabin, the measurements of whole-body vibrations were performed both during the return to port and while seated or on the cabin floor.

The boat areas and the activities identified for whole-body vibration measurements were agreed upon during an interview with the operating staff (Table 2).

\subsection{Questionnaire}

The 108 workers on fishing vessels filled out a questionnaire to collect data on the perception of occupational risk and self-perception of health conditions.

The questionnaire was designed and distributed via a pilot study with a sample of 25 fishermen. Based on this pilot study, the questions and the possible answers were revised. Qualified personnel administered the questionnaire to fishermen during their work activities. Before answering the questions, the participants who consented to the study were invited to attend a short briefing in which the purpose and methods of the study were presented. The survey was divided into four sections. The first section included general questions about age, sex, nationality, marital status, job title, daily working hours, and length of employment. The second section included questions regarding work and perception of occupational risk (e.g., excessive physical effort, noise, uncomfortable working conditions, quality of life), and in the last part of the questionnaire, workers were asked questions about self-perception of health conditions (e.g., visual disturbances, hearing disorders, skin changes, cardio-respiratory disorders, lower back pain) and training/information available at the workplace.

\section{Results}

\subsection{Biomechanical Overload}

There was found a high risk (red band), in particular, as Step 1 (repetitive/duration of movements) demonstrated that the 'work activity provides repetitive movements for more than $4 \mathrm{~h}$ total in a normal working day'. Step 4 (recovery periods) suggested that the work was carried out for more 
than $1 \mathrm{~h}$ continuously or without changing tasks. The following section describes the results achieved considering the main fishing techniques.

\subsubsection{Trawl Fishing}

Trawling is a fishing method that involves pulling a fishing net (generally a conical shape) through the water behind one or more boats. These nets rest on the bottom to collect the catch. Fishermen commonly use bottom trawls to catch shrimp and bottom-dwelling fish like halibut and sole.

The risk related to biomechanical overload is mainly due to handling manual loads, especially during the transport of fish from transom to refrigerator on the bow and from refrigerator to the quay. This working process can be repeated four or five times within every $24 \mathrm{~h}$ of activity. According to the ISO 11228-1 standard, the risk index of this task is $>0.9$. When risk index is between 0.76 and 1.25 the adoption of preventive measures proves to be not necessary [37].

The risk associated with repetitive hand-arm movements is mainly due to the selection of capture loads and placing the fish in boxes. According to the ISO 11228-3 standard, the risk index of this task for both upper limbs in the "light red band" (OCRA checklist method).

The dropping of fishing nets and the selection of catch were the tasks with major risks of awkward positions, classified in the "red band" (RULA method).

\subsubsection{Longline Fishing}

Longline fishing, or longlining, is a commercial fishing technique. It uses a long line, called the main line, with baited hooks attached at intervals by means of branch lines called snoods (or gangions). Longliners-fishing vessels rigged for longlining — commonly target swordfish, tuna, halibut, sablefish, and many other species.

The risk related to biomechanical overload is due to the transport of fish boxes (10 boxes with an average weight of $7 \mathrm{~kg}$ each) and the charging and discharging of longline boxes (three boxes with an average weight of $50 \mathrm{~kg}$ ). The loading, unloading and transport of loads are all carried out by hand in the absence of equipment aids.

According to the ISO 11228- 1 standard, the risk index of this task is $>0.9$ and therefore the adoption of preventive measures proves to be not necessary. The risk associated with repetitive hand-arm movements is related to lowering fishing hooks into the sea and their withdrawal (approximately 3000 hooks).

According to the ISO 11228-3 standard, the risk index of this task is classified in the "purple band" for the right upper limb and the "light red band" for the left upper limb. With regard to the withdrawal of hooks, the index risk is classified in the "red band".

\subsubsection{Mussel Cultivation}

Mussel cultivation was conducted using longlines. This system consists of a series of long horizontal thick ropes which are buoyed by a number of suitable floats. This equipment is anchored in place by concrete blocks. Thin vertical ropes to which the mussels (mussels row) are attached are hung from the horizontal lines.

The risks associated with handling manual loads occur during the withdrawal of mussel rows, placing them on conveyor belts, packaging mussel sacks, and transporting waste-product boxes. All these tasks are carried out by manual handling. According to the ISO 11228-1 standard, for this type of working activity the risk index is $>0.9$.

The risks related to awkward positions and repetitive hand-arm movements are due to mussel sieving, mussel row cutting on the conveyor belts, fishnet preparation, and sowing activities.

According to the ISO 11228-3 standard, the risk index of this task is classified in the "red band" for the right upper limb. 


\subsection{Noise}

According to the European Directive [38], in the workplace, the noise exposure limits that must not be exceeded are a daily or weekly exposure of 87 decibels (dB), taking into account any attenuation due to hearing protection.

The following tables contain, for each vessel, the measured values of Leq (A) with the relative exposure times and the exposure values calculated (LEX, W).

The levels of weekly noise exposure (LEX, W) exceed the exposure limit value of $87 \mathrm{dBA}$ for fishing workers. The activities with the highest sound levels—Leq dBA-were towing and hauling nets.

The highest value was found in the engine compartment (values between 106 and $109 \mathrm{dBA}$ ), while the sleeping berth had the least amount of noise (values between 70.5 and $78.8 \mathrm{dBA}$ ) (Table 3).

Table 3. Noise exposure of workers on fishing vessels.

\begin{tabular}{|c|c|c|c|c|c|c|c|}
\hline Activity/Measurement Station & $\begin{array}{c}\text { T exp } \\
\text { Sunday } \\
(\mathrm{m})\end{array}$ & $\begin{array}{c}\text { T exp } \\
\text { Weekdays } \\
(\mathrm{m})\end{array}$ & $\begin{array}{c}\text { Bari/01 } \\
\text { Leq } \\
\text { (dBA) }\end{array}$ & $\begin{array}{c}\text { Bari/02 } \\
\text { Leq } \\
\text { (dBA) }\end{array}$ & $\begin{array}{c}\text { Mola/04 } \\
\text { Leq } \\
\text { (dBA) }\end{array}$ & $\begin{array}{c}\text { Mola/05 } \\
\text { Leq } \\
\text { (dBA) }\end{array}$ & $\begin{array}{c}\text { Monopoli/06 } \\
\text { Leq } \\
\text { (dBA) }\end{array}$ \\
\hline Preparatory activities/winch & 10 & 10 & 83.2 & 84.0 & 80.8 & 77.2 & 78.6 \\
\hline Port departure/winch & 60 & 30 & 85.9 & 93.9 & 86.8 & 83.3 & 85.2 \\
\hline $\begin{array}{l}\text { Towing nets/winch } \\
\text { open engine room }\end{array}$ & 200 & 180 & 88.8 & 92.3 & 88.7 & 88.2 & 92.1 \\
\hline Return to port/control cabin & - & - & 81.7 & 81.2 & 79.0 & 78.8 & 79.4 \\
\hline Return to port/winch and open deck & 60 & 30 & 84.2 & 86.5 & 87.2 & 86.5 & 85.0 \\
\hline Towing nets/open deck & 270 & 260 & 90.6 & 88.9 & 82.4 & 84.8 & 85.3 \\
\hline LEX, W (dBA) Fishing workers & - & - & 89.3 & 90.3 & 87.5 & 87.3 & 89.9 \\
\hline Measurement uncertainty in LEX, W (dBA) & - & - & 3.4 & 3.1 & 3.2 & 3.2 & 3.3 \\
\hline
\end{tabular}

A noise frequency analysis was also conducted for the five vessels during the port exit phase. This analysis showed the following:

- High noise levels were approximately $63 \mathrm{~Hz}$; this frequency was due to engine operation (engine speed), and there was a noise decay between 800 and 20,000 Hz.

- Workers on fishing vessels are mainly exposed to low-frequency sounds $(<2000 \mathrm{~Hz})$.

\subsection{Whole Body Vibration}

The following table contains, for each vessel, the measured values of Aw(max) with the relative exposure times, and the daily exposure limit values (ELV) measured by a formula known as an $\mathrm{A}(8)$ value. The daily ELV is the average exposure (A) over $8 \mathrm{~h}(8)$ days and takes into account the magnitude of the vibration and the duration of its exposure.

During the whole-body vibration measurement procedures, we acquired the frequency values. Regarding whole-body vibrations, according to UNI ISO 2631-1, the considered values were those in the frequency range of $0.5-80 \mathrm{~Hz}$.

For workers on fishing vessels, exposure levels to whole-body vibrations were below the exposure limit values set by council directive 2002/44/EC $\left(<0.5 \mathrm{~m} / \mathrm{s}^{2}\right)$ (Table 4) [39]. The UNI ISO 5349 and UNI ISO 2631 standards underscore the need to calculate measurement uncertainty; however, within these documents, the calculation method for the uncertainty is not outlined, nor is there any reference to other texts. 
Table 4. Whole-body vibration exposure for workers on fishing vessels.

\begin{tabular}{|c|c|c|c|c|c|c|c|c|c|c|}
\hline \multirow{2}{*}{$\begin{array}{c}\text { Activity/Measurement } \\
\text { Station }\end{array}$} & \multicolumn{2}{|c|}{ Bari/01 } & \multicolumn{2}{|c|}{ Bari/02 } & \multicolumn{2}{|c|}{ Mola/04 } & \multicolumn{2}{|c|}{ Mola/05 } & \multicolumn{2}{|c|}{ Monopoli/06 } \\
\hline & $\begin{array}{c}\text { Aw } \\
(\max )\end{array}$ & $\begin{array}{c}\text { Recurrent T } \\
\operatorname{Exp} \operatorname{Max}(\mathrm{m})\end{array}$ & $\begin{array}{c}\text { Aw } \\
(\max )\end{array}$ & $\begin{array}{l}\text { Recurrent T } \\
\operatorname{Exp} \operatorname{Max}(\mathrm{m})\end{array}$ & $\begin{array}{c}\text { Aw } \\
(\max )\end{array}$ & $\begin{array}{c}\text { Recurrent T } \\
\operatorname{Exp} \operatorname{Max}(\mathrm{m})\end{array}$ & $\begin{array}{c}\text { Aw } \\
(\max )\end{array}$ & $\begin{array}{c}\text { Recurrent T } \\
\operatorname{Exp} \operatorname{Max}(\mathrm{m})\end{array}$ & $\begin{array}{c}\text { Aw } \\
(\max )\end{array}$ & $\begin{array}{r}\text { Recurrent T } \\
\text { Exp Max (m) }\end{array}$ \\
\hline Preparatory activities/winch & 0.25 & 10 & 0.25 & 10 & 0.07 & 10 & 0.15 & 10 & 0.22 & 10 \\
\hline Port departure/winch & 0.33 & 60 & 0.32 & 60 & 0.18 & 60 & 0.18 & 60 & 0.08 & 60 \\
\hline $\begin{array}{l}\text { Towing nets/winch, } \\
\text { open engine room }\end{array}$ & 0.35 & 200 & 0.07 & 200 & 0.11 & 200 & 0.32 & 200 & 0.10 & 200 \\
\hline $\begin{array}{l}\text { Towing nets/winch, } \\
\text { closed engine room }\end{array}$ & 0.15 & - & 0.07 & - & 0.13 & - & 0.23 & - & 0.15 & - \\
\hline $\begin{array}{l}\text { Return to port/winch and } \\
\text { open deck }\end{array}$ & 0.25 & 60 & 0.28 & 60 & 0.25 & - & 0.21 & - & 0.35 & - \\
\hline Towing nets/open deck & 0.34 & 270 & 0.07 & 270 & 0.23 & - & 0.11 & - & 0.12 & - \\
\hline Hauling nets/winch & 0.24 & 120 & 0.08 & 120 & 0.11 & 120 & 0.43 & 120 & 0.41 & 120 \\
\hline Hauling nets/berth & 0.27 & 120 & 0.35 & 120 & 0.27 & 120 & 0.20 & 120 & 0.10 & 120 \\
\hline $\begin{array}{c}\mathrm{A}(8)(\mathrm{m} / \mathrm{s} 2) \\
\text { Fishing workers }\end{array}$ & \multicolumn{2}{|r|}{0.41} & \multicolumn{2}{|r|}{0.25} & \multicolumn{2}{|r|}{0.26} & \multicolumn{2}{|r|}{0.34} & \multicolumn{2}{|r|}{0.27} \\
\hline
\end{tabular}


The analysis of these data showed the following:

- Whole-body vibration results showed a spike at $0.8 \mathrm{~Hz}$ related to wave-powered operation and a spike at $63 \mathrm{~Hz}$ related to engine operation.

- The high frequencies of vibration were concentrated at $1-2 \mathrm{~Hz}, 80 \mathrm{~Hz}$ and $800 \mathrm{~Hz}$.

\subsection{Questionnaire}

The 108 fishermen interviewed are all male, mostly married (72.3\%), with an average age of 49 years and average working age of 28 years. Data collected through the questionnaires on the perception of work risk and on the self-perception of health conditions showed the presence of the following: osteoarticular disorders (42\%), cardiovascular diseases $(24 \%)$, digestive disorders $(7 \%)$, urological diseases $(9 \%)$, diabetes $(6 \%)$, skin alterations $(4 \%)$, respiratory diseases $(3 \%)$, and other $(1 \%)$. The most common type of musculoskeletal symptom was back pain followed by shoulder joint pain, knee joint pain, and wrists joints pain (Table 5).

Table 5. Prevalence of musculoskeletal symptoms.

\begin{tabular}{cc}
\hline Symptoms & Prevalence \\
\hline Back pain & $43.5 \%$ \\
Shoulder joint pain & $23.0 \%$ \\
Knee joint pain & $16.5 \%$ \\
Wrists joints pain & $11.0 \%$ \\
Other & $6.0 \%$ \\
\hline
\end{tabular}

\section{Discussion}

In many countries, including Italy, the fishing sector has, at least in part, gaps in the systems of laws, regulations, and measures that protect the health and safety of workers. Because of this lack of attention from competent authorities, there are no exhaustive data on occupational hazards and health surveillance programmes [40-42].

The high prevalence of WMSDs in fisheries has been confirmed by several research studies [43-46]. A recent Danish study concluded that although there were improvements in working techniques, there were still no optimal ergonomic conditions in this sector, and workers on fishing vessels represent a professional cohort at high risk of WMSDs (e.g., pain in lower back, hands, or wrists) [47]. Although our study evaluated a significant number of risks on board fishing vessels, there were some limitations, such as the lack of personal exposure measurements with dosimeters and the absence of risk assessment of hand-harm vibrations considering ISO standard 5349. The results of the analysis of work cycles for the different fishing techniques and the data collected from the questionnaires on the perception of work risk and the self-perception of health conditions showed that workers on fishing vessels were exposed to a high risk of biomechanical overload resulting from different fishing tasks. In a study conducted in 2013, an interviewer-administered questionnaire was distributed to a random sample of 172 workers on fishing vessels in north-eastern Greece, and the authors found results comparable to ours [28]. In particular, the risks related to repetitive movements of the upper limbs were mainly due to the selection of catch, withdrawal of hooks and sieving of mussels, while the risks from the manual handling of loads were the greatest during the lifting and transporting fish and packing of mussel sacks. The high prevalence of MSDs among fishermen was also confirmed in a cross-selectional study conducted from August to October 2011 involving 465 Indian fishermen [27].

Analysis of the questionnaire data showed that the most frequent musculoskeletal symptom was back pain (43.5\%) followed by pain in the shoulder joint $(23 \%)$ and pain in the knee joint $(16.5 \%)$, in agreement with previous studies [43,47]. Instead, Harshani et al. (2015) found a higher prevalence of knee joint pain than that of joint pain in the shoulder [27]. 
The data obtained from the measurements performed on fishing boats in the Apulia region highlighted that the levels of weekly noise exposure (LEX,W) exceeded the exposure limit value of $87 \mathrm{dBA}$ for workers on fishing vessels. The activities with the highest sound levels Leq dBA were towing and hauling nets.

The highest sound level was found in the engine compartment (values between 106 and 109 dBA), while the sleeping berth had the least amount of noise (values between 70.5 and $78.8 \mathrm{dBA}$ ).

Rapisarda et al. conducted a phonometric survey aboard six fishing vessels carrying a crew of less than six fishing in the mid-Adriatic and they found that in the engine rooms the equivalent sound pressure level consistently exceeded $90 \mathrm{Db}(\mathrm{A})$ on all the vessels [21].

In addition, the data obtained from the study conducted on five ships of the Chioggia's fleet are in line with those of our study and confirm high sound levels in engine rooms followed by the central areas and the sterns of the fishing boats [22]. Some investigations carried out on board Norwegian ships also recorded noise levels between 96 and $108 \mathrm{dBA}$ in engine rooms and between 70 and $90 \mathrm{dBA}$ in control cabins [20]. A recent study carried out on the Gulf coast fishing vessels highlighted dangerous noise levels in the same engine rooms (values between 94.8 and $105.0 \mathrm{dBA}$ ) and a significant hearing loss for fishermen with most experience in fishing activity [23].

The engine room is an important source of noise on board fishing vessels because it is responsible for propelling ship and generating electric power. Kaerlev et al. showed that noise-induced hearing loss was a frequent health problem among men working in the engine rooms of ships and showed that compared to other seafarers, engine room staff had a relative risk ratio of 2.39 (95\% CI: 1.74-3.26) [48].

As exposure to loud noises, such as in engine rooms, is unavoidable on fishing boats, hearing protection within these areas is mandatory. Devices for hearing protection including earplugs or earmuffs can be easily sourced and used on board [49]. Neitzel et al. showed that the use of hearing protector devices during working activities reduced the average exposure by about $10 \mathrm{dBA}$, but not all workers wore them consistently due to communication demands [50].

Although we found different noise levels among the various areas of the ships, there is no soundproofed engine room on our fishing vessels and the noise is easily transmitted to the close rooms, especially in the smaller fishing vessels.

The frequency analysis of noise showed that the workers on fishing vessels were mainly exposed to low-frequency sounds $(<2000 \mathrm{~Hz})$. These data were in contrast with the measured data from industrial activities [51]. Noise pollution has negative effects on environmental and human health. Low-frequency sounds associated with constant noise exposure could result in acoustic damage, cardiovascular and gastric disorders, and sleep disorders (extra-auditory effects) [52-54]. For fish, whales, and other marine animals, intense underwater noises caused by explosions can cause acoustic trauma and even death. Furthermore, noises from ships and boats can disturb their ability to find food, mates, or avoid predators [55,56].

On board fishing vessels, workers are also exposed to vibration for long and continuous periods. These vibrations may cause several negative effects on human health, such as pain in the back, neck, hands, shoulders and hips, as well as cardiovascular and gastrointestinal problems [57-59].

Pinto et al found that daily exposure to vibrations on board fishing vessels varied according to sea conditions with values ranging between 0.2 and $0.3 \mathrm{~m} / \mathrm{s}^{2}$ [26]. This data is in line with the results of our study.

Even if the values recorded on the fishing vessels did not exceed the action level $\left(0.5 \mathrm{~m} / \mathrm{s}^{2}\right)$ established by the European Directive, workers were subjected to constant muscle tension. Several studies demonstrate that awkward body positions which increase muscle tension during working activities contributes to the onset of musculoskeletal disorders [60-62]. This phenomenon is due to excessive force on the joints and overload the muscles and tendons around the articulation performed. However, these results cannot be obtained from our study. 
The strength of the study lies in analysing three important risks to which fishermen are exposed in the context of a region with high fishing activity. The study showed that fishery workers have a high prevalence of work-related diseases that must be carefully assessed in the context of health surveillance. Although our study assessed a significant number of risks on board the vessels, there were some limitations. In particular, there are no personal exposure measurements with dosimeters and a not very large sample. Furthermore, there were difficulties in finding more technical information on fishing vessels (not accessible at the time of the study) and in recruiting participants. The low level of education of the fishermen who participated in the survey may have a negative effect on their awareness of the topic of the study and on the quality of the data provided by them. Moreover, it was difficult to have a qualified staff prepared to face the difficult working conditions to which these workers are exposed.

\section{Conclusions}

The preliminary data of this study suggest that workers on fishing vessels are exposed to numerous risks. In particular, risks related to biomechanical overload, noise and whole-body vibrations represent major health problems for workers on fishing vessels. Knowledge about occupational hazards in the fishing sector and the consequent health effects should be utilized to improve vessels and develop new technologies. Moreover, these data can be used to raise awareness of the correct use of personal protective equipment, and to carry out adequate health surveillance of workers exposed to these occupational risks.

Author Contributions: F.M., E.S.S.C., A.C., and L.D.M. wrote the manuscript; L.V. and D.C. revised it; L.L. curated the data; D.C. supervised the project; L.V. administered the project. All authors read and approved the final manuscript.

Conflicts of Interest: The authors declare no conflict of interest.

\section{References}

1. Food and Agriculture Organization of the United Nations. The State of World Fisheries and Aquaculture 2018-Meeting the Sustainable Development Goals; Food and Agriculture Organization of the United Nations: Rome, Italy, 2018.

2. FAO Fisheries and Aquaculture Department. Fishery and Aquaculture Country Profiles. Italy; Country Profile Fact Sheets; FAO Fisheries and Aquaculture Department: Rome, Italy, 2014.

3. Forestry and Fishing Sector "Analysis of Work-Related Injury and Illness, 2001 to 2014". Available online: https://econpapers.repec.org/bookchap/esrresser/bkmnext358.htm (accessed on 16 December 2019).

4. International Labour Organization. Safety and Health in the Fishing Industry; International Labour Office: Geneva, Switzerland, 1999.

5. WHO. Prevention and Control. Exchange (PACE); A document for Decisions Makers; World Health Organisation, Office of Occupational Health, Division of Health Promotion, Education and Promotion: Geneva, Switzerland, 1995.

6. Intranuovo, G.; De Maria, L.; Facchini, F.; Armenise, G.; Caputi, A.; Birtolo, F.; Vimercati, L. Risk assessment of upper limbs repetitive movements in a fish industry. BMC Res. Notes 2019, 12, 354. [CrossRef] [PubMed]

7. Silvetti, A.; Mufanò, E.; Ranavolo, A.; Tatarelli, A.; Fiori, L.; Iavicolo, S.; Di Palma, P.; Draicchio, F. Ergonomic Risk Assessment of Sea Fisherman Part III: Manual Handling and Static Posture. In Advances in Social and Occupational Ergonomics; AHFE 2019. Advances in Intelligent Systems and Computing; Goossens, R., Murata, A., Eds.; Springer: Cham, Switzerland, 2019; Volume 970.

8. Lorusso, A.; Vimercati, L.; L'Abbate, N. Musculoskeletal Complaints Among Italian X-Ray Technology Students: A Cross-Sectional Questionnaire Survey. BMC Res. Notes 2010, 3, 1-4. [CrossRef] [PubMed]

9. Heidari, M.; Borujeni, M.G.; Rezaei, P.; Abyaneh, S.K. Work-Related Musculoskeletal Disorders and Their Associated Factors in Nurses: A Cross-Sectional Study in Iran. Malays. J. Med. Sci. 2019, 26, 122-130. [CrossRef] [PubMed]

10. E-fact 55: Safe. Maintenance of Fishing Vessels. Available online: https://osha.europa.eu/en/publications/efact-55-safe-maintenance-fishing-vessels/view (accessed on 16 December 2019). 
11. Case Studies in Environmental Medicine: Toxicity of Polycyclic Aromatic Hydrocarbons (PAHs). Available online: https://www.atsdr.cdc.gov/csem/csem.asp?csem=13\&po=3 (accessed on 16 December 2019).

12. Serio, G.; Pezzuto, F.; Marzullo, A.; Scattone, A.; Cavone, D.; Punzi, A.; Fortarezza, F.; Gentile, M.; Buonadonna, A.L.; Barbareschi, M.; et al. Peritoneal mesothelioma with residential asbestos exposure. Report of a case with long survival (seventeen years) analyzed by Cgh-array. Int. J. Mol. Sci. 2017, 18, 1818. [CrossRef]

13. Vimercati, L.; Carrus, A.; Bisceglia, L.; Tatò, I.; Bellotta, M.R.; Russo, A.; Martina, G.; Daprile, C.; Di Leo, E.; Nettis, E.; et al. Biological monitoring and allergic sensitization in traffic police officers exposed to urban air pollution. Int. J. Immunopathol. Pharmacol. 2006, 19, 57-60.

14. Campo, L.; Vimercati, L.; Carrus, A.; Bisceglia, L.; Pesatori, A.C.; Bertazzi, P.A.; Assennato, G.; Fustinoni, S. Environmental and Biological Monitoring of PAHs Exposure in Coke-Oven Workers at the Taranto Plant Compared to Two Groups from the General Population of Apulia, Italy. Med. Del. Lavoro 2012, 103, 347-360.

15. Vimercati, L. Traffic related air pollution and respiratory morbidity. Lung India 2011, 28, 238. [CrossRef]

16. International Agency for Research on Cancer. Some inorganic and organometallic compounds. In Monographs on the Evaluation of the Carcinogenic Risk of Chemicals to Man; WHO/IARC: Lyon, France, 1973; Volume 2, pp. 17-47.

17. Italian Ministry of Agricultural, Food and Forestry Policies. Directorate-General for Fisheries and Aquaculture. Investigation. Maritime Activities and Health Aspects. In Workers 'Aging: Social and Economic Aspects of Maritime Fisheries; Aging Society-Third Observatory: Roma, Italy, 2009.

18. Adeguamento della Normativa Sulla Sicurezza e Salute dei Lavoratori Marittimi a Bordo delle Navi Mercantili da Pesca Nazionali, a Norma Della L. 31 Dicembre 1998, n. 485. Available online: https://www.camera.it/ parlam/leggi/deleghe/testi/99271dl.htm (accessed on 16 December 2019).

19. Attuazione Della Direttiva 93/103/CE Relativa alle Prescrizioni Minime di Sicurezza e di Salute per il Lavoro a Bordo Delle Navi da Pesca. Available online: https:/www.camera.it/parlam/leggi/deleghe/testi/99298dl.htm (accessed on 16 December 2019).

20. Svendsen, K.; Borresen, F. Measurements of mineral oil mist, hydrocarbon vapor, and noise in engine rooms of ship. Appl. Occup. Environ.Hyg. 1999, 14, 186-189. [CrossRef]

21. Rapisarda, V.; Valentino, M.; Bolognini, S.; Fenga, C. Noise-related occupationalrisk aboard fishing vessels: Considerations on prevention and the protection of exposed workers. G Ital. Med. Lavoro Ergon. 2004, 26, 191-196. (In Italian)

22. Peretti, A.; Nataletti, A.; Bonfiglio, P.; di Bisceglie, A.P. Rumore nei battelli da pesca. G Ital. Med. Lavoro Ergon. 2013, 35, 215-218.

23. Levin, J.L.; Curry, W.F., 3rd; Shepherd, S.; Nalbone, J.T.; Nonnenmann, M.W. Hearing Loss and Noise Exposure among Commercial Fishermen in the Gulf Coast. J. Occup. Environ. Med. 2016, 58, 306-313. [CrossRef] [PubMed]

24. Basner, M.; Babisch, W.; Davis, A.; Brink, M.; Clark, C.; Janssen, S.; Stansfeld, S. Auditory and non-auditory effects of noise on health. Lancet 2014, 383, 1325-1332. [CrossRef]

25. Bernardini, M.; Fredianelli, L.; Fidecaro, F.; Gagliardi, P.; Nastasi, M.; Licitra, G. Noise Assessment of Small Vessels for Action Planning in Canal Cities. Environments 2019, 6, 31. [CrossRef]

26. Pinto, I.; Stacchini, N. Il rischio vibrazioni nelle attività marittime e portuali. G Ital. Med. Lavoro Ergon. 2013, 35, 211-214.

27. Harshani, S.R.; Abeysena, C. Musculoskeletal symptoms, skin disorders and visual impairment among fishermen in the Divisional Secretariat Division of Kalpitiya. Ceylon Med. J. 2015, 60, 90-94. [CrossRef]

28. Frantzeskou, E.; Jensen, O.C.; Linos, A. Health status and occupational risk factors in Greek small fisheries workers. Int. Marit. Health 2016, 67, 137-143. [CrossRef]

29. Available online: https://www.inail.it/cs/internet/docs/det414-2017.pdf (accessed on 5 September 2019).

30. Mechanical Vibration and Shock-Evaluation of Human Exposure to Whole Body Vibration. Part. 1: General Requirement. Available online: https://www.iso.org/standard/76369.html (accessed on 16 December 2019).

31. Mechanical Vibration and Shock—Evaluation of Human Exposure to Whole Body Vibration Part. 2: Vibration in Buildings (1 Hz to $80 \mathrm{~Hz}$ ). Available online: https://www.iso.org/standard/23012.html (accessed on 16 December 2019). 
32. Evaluation of Human Exposure to Whole-Body Vibration-Part. 3: Evaluation of Exposure to Whole-Body z-Axis Vertical Vibration in the Frequency Range 0.1 to $0.63 \mathrm{hz}$. Available online: https://www.iso.org/ standard/7615.html (accessed on 16 December 2019).

33. Colombini, D.; Occhipinti, E.; Cerbai, M.; Battevi, N.; Placci, M. Aggiornamento di procedure e di criteri di applicazione della Checklist OCRA. Med. Lavoro 2011, 102, 1. Available online: http://www.ergonomiesite. be/documenten/repetitief/Revised-OCRA-Checklist-Book.pdf (accessed on 28 November 2019).

34. Mcatamney, L.; Corlett, N. RULA: A survey method for the investigation of work-related upper limb disorders. Applied Ergonomics 1993, 24, 91-92. [CrossRef]

35. ISO 9612:2009. Acoustics—Determination of Occupational Noise Exposure-Engineering Method, 2nd ed.; ISO: Geneva, Switzerland, 2009.

36. Determination of Occupational Noise Exposure-Engineering Method. Available online: https://www.iso. org/obp/ui/es/\#iso:std:iso:9612:ed-2:v1:en (accessed on 16 December 2019).

37. Colombini, D.; Occhipinti, E.; Ciroli, S.; Menoni, O.; Ricci, M.G.; Battevi, N.; Violante, F.S.; Matteoli, S.; Draicchio, F. Linee Guida SIMLII per la Prevenzione dei Disturbi e delle Patologie Muscolo-Scheletriche del Rachide da Movimentazione Manuale dei Carichi; PIME Editrice: Pavia, Itatly, 2004.

38. Directive 2003/10/EC of the European Parliament and of the Council of 6 February 2003 on the minimum health and safety requirements regarding the exposure of workers to the risks arising from physical agents (noise) (Seventeenth individual Directive within the meaning of Article 16(1) of Directive 89/391/EEC). 2003. Available online: https://eur-lex.europa.eu/legal-content/EN/ALL/?uri=CELEX\%3A32003L0010 (accessed on 16 December 2019).

39. Directive 2002/44/EC of the European Parliament and of the Council of 25 June 2002 on the minimum health and safety requirements regarding the exposure of workers to the risks arising from physical agents (vibration) (sixteenth individual Directive within the meaning of Article 16(1) of Directive 89/391/EEC)—Joint Statement by the European Parliament and the Council. 2002. Available online: https:/eur-lex.europa.eu/ legal-content/EN/ALL/?uri=CELEX\%3A32002L0044 (accessed on 16 December 2019).

40. Pena, P.G.; Gomez, C.M. Health of subsistence fishermen and challenges for Occupational Health Surveillance. Cien Saude Colet 2014, 19, 4689-4698, (In English, Portuguese). [CrossRef]

41. Grimsmo-Powney, H.; Harris, E.C.; Reading, I.; Coggon, D. Occupational health needs of commercial fishermen in South West England. Occup. Med. (Lond.) 2010, 60, 49-53. [CrossRef]

42. Italian Institute of Occupational Accident Insurance (INAIL). Ministry of Infrastructure and Transport. Second Fisheries Report, 2010; Tipografia INAIL: Milano, Italy, 2011; Available online: https://www.inail.it/cs/ internet/docs/alg-secondo-rapporto-pesca.pdf (accessed on 16 December 2019).

43. Dabholkar, T.A.; Nakhawa, P.; Yardi, S. Common musculoskeletal problem experienced by fishing industry workers. Indian J. Occup. Environ. Med. 2014, 18, 48-51. [CrossRef] [PubMed]

44. Musculoskeletal Disorders in Fisheries. Available online: https://oshwiki.eu/wiki/Musculoskeletal_disorders_ in_fisheries (accessed on 16 December 2019).

45. Kaerlev, L.; Jensen, A.; Sabro Nielsen, P.; Olsen, J.; Hannerz, H.; Tüchsen, F. Hospital contacts for injuries and musculoskeletal diseases among seamen and fishermen: A population-based cohort study. BMC Musculoskelet. Disord. 2008, 9, 8. [CrossRef] [PubMed]

46. Østergaard, H.; Jepsen, J.R.; Berg-Beckhoff, G. The workload of fishermen: A cross sectional survey among Danish commercial fishermen. Int. Marit. Health 2016, 67, 97-103. [CrossRef]

47. Berg-Beckhoff, G.; Østergaard, H.; Jepsen, J.R. Prevalence and predictors of musculoskeletal pain among Danish fishermen-Results from a cross-sectional survey. J. Occup. Med. Toxicol. 2016, 11, 51, eCollection 2016. [CrossRef]

48. Kaerlev, L.; Jensen, A.; Nielsen, P.; Olsen, J.; Hannerrz, H.; Tuchsen, F. Hospital contacts for noise related hearing loss among Danish seafarers and fishermen: A population based cohort study. Noise Health 2008, 10, 41-45. [CrossRef]

49. Turan, O.; Helvacioglu, I.H.; Insel, M.; Khalid, H.; Kurt, R.E. Crew noise exposure on board ships and comparative study of applicable standards. Ships Offshore Struct. 2011, 6, 323-338. [CrossRef]

50. Neitzel, R.L.; Berna, B.E.; Seixas, N.S. Noise exposures aboard catcher/processor fishing vessels. Am. J. Ind. Med. 2006, 49, 624-633. [CrossRef] 
51. Reinhold, K.; Kalle, S.; Paju, J. Exposure to high or low frequency noise at workplaces: Differences between assessment, health complaints and implementation of adequate personal protective equipment. Agron. Res. 2014, 12, 895-906.

52. Lin, C.Y.; Tsai, P.J.; Lin, K.Y.; Chen, C.Y.; Chung, L.H.; Wu, J.L.; Guo, Y.L. Will daytime occupational noise exposures induce nighttime slee disturbance? Sleep Med. 2018, 50, 87-96. [CrossRef]

53. Rapisarda, V.; Ledda, C.; Ferrante, M.; Fiore, M.; Cocuzza, S.; Bracci, M.; Fenga, C. Blood pressure and occupational exposure to noise and lead (pb): A cross-sectional study. Toxicol. Ind. Health 2016, 32, 1729-1736. [CrossRef]

54. Münzel, T.; Schmidt, F.P.; Steven, S.; Herzog, J.; Daiber, A.; Sørensen, M. Environmental Noise and the Cardiovascular System. J. Am. Coll. Cardiol. 2018, 71, 688-697. [CrossRef] [PubMed]

55. The Impact of Ocean. Noise Pollution on Fish. and Invertebrates. Available online: https://tethys.pnnl.gov/ publications/impact-ocean-noise-pollution-fish-and-invertebrates (accessed on 16 December 2019).

56. Albera, R.; Bin, I.; Cena, M.; Dagna, F.; Giordano, P.; Sammartano, A. Gli effetti extra-uditivi del rumore. G Ital. Med. Lavoro Ergon. 2011, 33, 345-347.

57. Nakamura, H.; Katoh, A.; Nohara, S.; Nakamura, H.; Okada, A. Experimental studies on the pathogenesis of the gastric mucosal lesions induced by whole-body vibration. Environ. Res. 1992, 58, 220-229. [CrossRef]

58. Aoyama, A.; Yamaoka-Tojo, M.; Obara, S.; Shimizu, E.; Fujiyoshi, K.; Noda, C.; Matsunaga, A.; Ako, J. Acute Effects of Whole-Body Vibration Training on Endothelial Function and Cardiovascular Response in Elderly Patients with Cardiovascular Disease. Int. Heart J. 2019, 60, 854-861. [CrossRef]

59. Johanning, E. Whole-body vibration-related health disorders in occupational medicine-an international comparison. Ergonomics 2015, 58, 1239-1252. [CrossRef]

60. Lop, N.S.; Kamar, I.F.M.; Aziz, M.N.A.; Abdullah, L.; Akhir, N.M. Work-related to musculoskeletal disorder amongst Malaysian construction trade workers: Bricklayers. In AIP Conference Proceedings; AIP Publishing: Melville, NY, USA, 2017. [CrossRef]

61. Hossain, M.D.; Aftab, A.; Al Imam, M.H.; Mahmud, I.; Chowdhury, I.A.; Kabir, R.I.; Sarker, M. Prevalence of work related musculoskeletal disorders (WMSDs) and ergonomic risk assessment among readymade garment workers of Bangladesh: A cross sectional study. PLoS ONE 2018, 13, e0200122. [CrossRef]

62. Milhem, M.; Kalichman, L.; Ezra, D.; Alperovitch-Najenson, D. Work-related musculoskeletal disorders among physical therapists: A comprehensive narrative review. Int. J. Occup. Med. Environ. Health 2016, 29, 735-747. [CrossRef] 